\section{Expression pattern of thymosin beta 4 in the adult human liver}

\author{
S. Nemolato, ${ }^{1}$ P. Van Eyken, ${ }^{2}$ T. Cabras, ${ }^{3}$ \\ F. Cau, ${ }^{1}$ M.U. Fanari, ${ }^{1}$ A. Locci, ${ }^{1}$ \\ D. Fanni, ${ }^{1}$ C. Gerosa, ${ }^{1}$ I. Messana, ${ }^{3}$ \\ M. Castagnola, ${ }^{4}$ G. Faa ${ }^{1}$ \\ 'Dipartimento di Citomorfologia, \\ Divisione di Anatomia Patologica, \\ Università di Cagliari, Italy; ${ }^{2}$ Department \\ of Pathology, K.U. Leuven, Belgium; \\ ${ }^{3}$ Dipartimento di Scienze Applicate ai \\ Biosistemi, Università di Cagliari, Italy; \\ ${ }^{4}$ Dipartimento di Biochimica Clinica, \\ Universita Cattolica di Roma, Italy
}

\section{Abstract}

Thymosin beta-4 (T $\beta 4)$ is a member of betathymosins, a family of small peptides involved in polymerization of G-actin, and in many critical biological processes including apoptosis, cell migration, angiogenesis, and fibrosis. Previous studies in the newborn liver did not reveal any significant reactivity for $\mathrm{T} \beta 4$ during the intrauterine life. The aim of the present study was to investigate by immunohistochemistry T $\beta 4$ expression in the adult normal liver. Thirty-five human liver samples, including 11 needle liver biopsies and 24 liver specimens obtained at autopsy, in which no pathological change was detected at the histological examination, were immunostained utilizing an anti-T $\beta 4$ commercial antibody. $\mathrm{T} \beta 4$ was detected in the hepatocytes of all adult normal livers examined. A zonation of T $\beta 4$ expression was evident in the vast majority of cases. Immunostaining was preferentially detected in zone 3 , while a minor degree of reactivity was detected in periportal hepatocytes (zone 1). At higher power, T $\beta 4$-reactive granules appeared mainly localized at the biliary pole of hepatocytes. In cases with a strong immunostaining, even perinuclear areas and the sinusoidal pole of hepatocytes appeared interested by immunoreactivity for $\mathrm{T} \beta 4$. The current work first evidences a strong diffuse expression of $\mathrm{T} \beta 4$ in the adult human liver, and adds hepatocytes to the list of human cells able to synthesize large amounts of $\mathrm{T} \beta 4$ in adulthood. Moreover, T $\beta 4$ should be added to the liver proteins characterized by a zonate expression pattern, in a descending gradient from the terminal vein to the periportal areas of the liver acinus. Identifying the intimate role played by this peptide intracellularly and extracellularly, in physiology and in different liver diseases, is a major challenge for future research focusing on $\mathrm{T} \beta 4$.

\section{Introduction}

Thymosin beta 4 (T $\beta 4$ ) is a member of thymosins, ${ }^{1}$ a versatile family of small peptides expressed in most mammalian cells. ${ }^{2}$ It shows a high intracellular concentration, in cells able to rapidly increase their motility, like polymorphonuclear leukocytes, macrophages ${ }^{3,4}$ and mast cells. ${ }^{5}$ There exist about 15 highly homologous $\beta$-thymosin variants, containing 40 to 44 amino acid residues, that are found not only inside of cells but also in extracellular fluids, such as blood serum, ${ }^{6}$ saliva, ${ }^{7}$ wound fluid, ${ }^{8}$ and lacrimal secretion. ${ }^{9}$ Among thymosin peptides, $\mathrm{T} \beta 4$ is considered the most abundant in mammalian tissues: its activity has been mainly correlated with the regulation of actin polymerization in living cells. ${ }^{10} \mathrm{~T} \beta 4$ is thought to be also involved in many critical biological processes including angiogenesis, ${ }^{11}$ wound healing, ${ }^{12}$ inflammatory response ${ }^{13}$ and cell migration. ${ }^{14}$ Similarly, T $\beta 4$ activity was implicated in differentiation of hematopoietic cells,${ }^{15}$ in carcinogenesis, ${ }^{16}$ in apoptosis,${ }^{17}$ and in blood coagulation. ${ }^{18}$

Recently, many authors have proposed the $\mathrm{T} \beta 4$ involvement in the process of determining fibrosis in different organs. In mice with ureteral obstruction, $\mathrm{T} \beta 4$ has been shown to have profibrotic effects, while its metabolite Ac-SDKP showed anti-fibrotic actions. ${ }^{19}$ In human hepatic stellate cells in culture, T $\beta 4$ showed antifibrogenic effects, mediated by upregulation of the expression of hepatocyte grow factor (HGF) and by downregulation of the expression of platelet-derived growth factor- $\beta$ (PDGF- $\beta$ ) receptor. ${ }^{20} \mathrm{~A}$ recent study from our group carried out on the human newborn liver did not reveal any significant reactivity for T $\beta 4$ in the vast majority of liver cells during gestation and at birth. ${ }^{21}$

On the basis of these data, and given the previously reported ability of thymosins to change their expression pattern at different ages, it seemed of some interest to investigate by immunohistochemistry the $\mathrm{T} \beta 4$ expression pattern in the adult liver, in order to shed light on the role played by liver cells in the synthesis of this peptide.

\section{Materials and Methods}

The study included archived paraffinembedded liver sections obtained from 35 subjects. The cohort included 11 needle liver biopsies, performed on different clinical settings, in which no sign of liver pathology was detected at the histological examination, and 24 liver samples obtained in autopsy patients who died for different extrahepatic aetiologies, in which
Correspondence: Dr. Sonia Nemolato, Dipartimento di Citomorfolgia, Sezione di Anatomia Patologica, AOU San Giovanni di Dio, via Ospedale 54, 09124 Cagliari, Italy.

Tel. +39.070 .6092370 - Fax: +39.070 .657882 .

E-mail: sonianemolato@libero.it

Key words: $\beta$-Thymosins, T $\beta 4$, human liver.

Acknowledgments: the authors would express their deep gratitude to Prof. Matteo Fraschini (University of Cagliari) for critical suggestions. They also want to thank Ms. Sandra Serra, Simonetta Paderi and Rossana Zedda for technical assistance and Mr. Ignazio Ferru for administrative support. This study was supported by Fondazione Banco di Sardegna.

Contributions: SN, PVE, IM, MC, GF research design, manuscript writing, revising and final approval; SN, PVE, TC, DF, CG research performing; FC, MUF, AL contributing to reagents/analytic tools; SN, PVE, TC, DF, CG, IM, MC, GF, data analysis.

Conflict of interest: the authors report no conflicts of interest.

Received for publication: 26 February 2011. Accepted for publication: 6 June 2011.

This work is licensed under a Creative Commons Attribution NonCommercial 3.0 License (CC BYNC 3.0).

(C) Copyright S. Nemolato et al., 2011

Licensee PAGEPress, Italy

European Journal of Histochemistry 2011; 55:e25 doi:10.4081/ejh.2011.e25

careful macroscopic and histological examination of liver sections did not evidence any significant pathological change. The age of subjects (24 males and 11 females) ranged from 29 up to 77 years. Clinical data at the basis of the decision of performing liver biopsies are reported in Table 1; the cause of death of the 24 autopsy cases is reported in Table 2 . All liver samples were routinely formalin-fixed and paraffin-embedded.

Staining of formalin-fixed, paraffin-embedded $5 \mu \mathrm{m}$ sections for T $\beta 4$ was performed essentially as previously described. ${ }^{5}$ Briefly, slides were deparaffinized, rehydrated, and endogenous peroxidase activity was quenced (30 min) by $0.3 \%$ hydrogen peroxide in methanol. Slides were then subjected to antigen retrival by boiling $(20 \mathrm{~min})$ in $10 \mathrm{mM}$ citrate buffer, $\mathrm{pH} 6$. Slides were incubated with $10 \%$ normal goat serum in phosphate buffered saline (PBS) for 60 min to block nonspecific binding, followed by incubation $(20 \mathrm{~h}$, $4^{\circ} \mathrm{C}$ ) with polyclonal anti-thymosin beta 4 antibody (Bachem-Peninsula Lab, San Carlos, CA, USA) diluted 1:100 in blocking solution. Slides were extensively washed with PBS con- 
taining $0.01 \%$ Triton X-100 and incubated with a secondary reagent (Envision kit) according to the manufacturer's (Dako, Glostrup, Denmark) instructions. After additional washes, color was developed using AEC reagent (Dako), sections were counterstained with hematoxylin and mounted. Immunostained specimens were examined by two pathologists (GF, SN). A semiquantitative grading system for the evaluation of $\mathrm{T} \beta 4$ immunoreactivity has been applied: $+=$ focal weak staining; $++=$ diffuse weak staining; $+++=$ diffuse strong staining. Zone 3 (periterminal hepatocytes) and zone 1 (periportal hepatocytes) were independently analyzed for $\mathrm{T} \beta 4$ immunoreactivity.

\section{Results}

$\mathrm{T} \beta 4$ reactivity was detected in all normal liver biopsies of adult subjects studied. No significant difference was observed between bioptic and autoptic liver examined. No relationship was found between the degree of T $\beta 4$

Table 1. clincal and immunohistochemical data of 11 liver needle biopsies characterized at histology by absent or minimal changes. $+=$ weak and focal; $++=$ weak and diffuse; $+++=$ strong and diffuse.

\begin{tabular}{cccccc} 
Case n. & Age & Sex & Clinical diagnosis & Grade of TB4 immunostaining Zone 3 & Grade of TB4 immunostaining Zone 1 \\
1 & 40 & M & HCV & + & - \\
2 & 36 & M & HBV + HCV & + & - \\
\hline 3 & 67 & F & HBV & + & - \\
4 & 64 & M & HCV & ++ & + \\
\hline 5 & 27 & M & Cholestasis & + & - \\
6 & 38 & F & HCV & ++ & - \\
\hline 7 & 45 & F & HBV/HCV & +++ & + \\
8 & 53 & M & Suspicious for neoplasia & ++ & ++ \\
\hline 9 & 51 & F & Surrounding of FNH & + & + \\
10 & 46 & F & Surrounding of adenoma & HCV & - \\
\hline 11 & 38 & M & & & +
\end{tabular}

Table 2. Clinical and immunohistochemical data regarding 25 liver samples obtained at autopsy, all characterized at histology by absent or minimal changes. $+=$ weak and focal; $++=$ weak and diffuse; $+++=$ strong and diffuse.

\begin{tabular}{|c|c|c|c|c|c|}
\hline Case n. & Age & Sex & Clinical diagnosis & Grade of TB4 immunostaining Zone 3 & Grade of TB4 immunostaining Zone 1 \\
\hline 1 & 83 & M & Heart attack & +++ & ++ \\
\hline 2 & 59 & M & Heart attack & +++ & ++ \\
\hline 3 & 62 & $\mathrm{~F}$ & Cardiac Infarction & ++ & + \\
\hline 4 & 60 & M & Pneumonia & ++ & + \\
\hline 5 & 43 & M & Heart attack & ++ & + \\
\hline 6 & 73 & $\mathrm{~F}$ & Heart attack & ++ & ++ \\
\hline 7 & 31 & M & 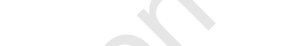 & ++ & + \\
\hline 8 & 32 & M & Pulmonary embolism & ++ & + \\
\hline 9 & 68 & $\mathrm{~F}$ & Heart attack & $+/-$ & - \\
\hline 10 & 50 & M & 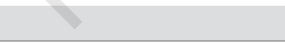 & + & - \\
\hline 11 & 45 & $\mathrm{~F}$ & Haemopericardium & + & + \\
\hline 12 & 91 & $\mathrm{~F}$ & Heart attack & ++ & + \\
\hline 13 & 81 & M & Aortic aneurism & +++ & ++ \\
\hline 14 & 58 & $\mathrm{~F}$ & Sepsis & ++ & + \\
\hline 15 & 71 & $\mathrm{~F}$ & Respiratory insufficiency & ++ & + \\
\hline 16 & 49 & M & Heart attack & +++ & ++ \\
\hline 17 & 61 & M & Pulmonary embolism & ++ & + \\
\hline 18 & 53 & M & Heart rupture & + & - \\
\hline 19 & 78 & M & Brain haemorrage & ++ & + \\
\hline 20 & 67 & $\mathrm{~F}$ & Pulmonary embolism & ++ & + \\
\hline 21 & 80 & $\mathrm{~F}$ & Brain haemorrage & ++ & - \\
\hline 22 & 47 & M & Pneumonia & ++ & + \\
\hline 23 & 75 & M & Intestinal infarct & ++ & + \\
\hline 24 & 53 & $\mathrm{~F}$ & Post-haemorragic shock & ++ & + \\
\hline 25 & 49 & M & Heart attack & ++ & + \\
\hline
\end{tabular}


immunostaining and age or sex of the subjects. Immunoreactivity for the peptide was mainly localized in the cytoplasm of hepatocytes, appearing as large granules different in shape and size. At low power, in the vast majority of cases, immunoreactivity for $\mathrm{T} \beta 4$ was not homogeneously diffuse to the entire parenchyma: it was mainly stored in periterminal hepatocytes (zone 3 of the acinus) while a minor degree of reactivity was detected in periportal hepatocytes (zone 1) (Figure 1). We often detected a zonation of $\mathrm{T} \beta 4$ expression, characterized by a progressive increase in the degree of immunostaining from the periportal to the periterminal areas, intermediate levels of $\mathrm{T} \beta 4$ immunostaining being observed in the hepatocytes of acinar zone 2 . In some cases (see Table 1 and Table 2), the periportal hepatocytes did not show any reactivity for the peptide: in these cases, only a mild reactivity for the peptide was found in zone 3 liver cells, indicating a strict correlation between $\mathrm{T} \beta 4$ storage in the different acinar zones. The degree of reactivity changed from one case to the next. In some cases only the periterminal hepatocytes were reactive for the peptide (Figure 2), while in other cases even periportal hepatocytes were immunostained (Figure 3). T $\beta 4$-reactive intracytoplasmic granules appeared mainly localized at the biliary pole of hepatocytes (Figure 4). In cases with a strong immunostaining, even perinuclear areas and the sinusoidal pole of hepatocytes appeared interested by $\mathrm{T} \beta 4$ overload (Figure 5). Even the size of T $\beta 4$ granules changed from one case to the next, the largest immunoreactive granules constantly being observed in cases characterized by the highest levels of reactivity for the peptide (Figure 5). The vast majority of stored peptide was constantly found inside the cytoplasm of the hepatocytes, in the absence of significant $\mathrm{T} \beta 4$ staining in Kupffer cells and in Ito cells.

\section{Discussion}

For some decades from the discovery of T $\beta 4$ in the calf thymus in $1965,{ }^{22}$ researchers have looked at its distribution in different organs and tissues and asked, what does it mean? To date, the majority of attempts to elucidate the mechanism of action of T $\beta 4$ in living organisms has come from the perspective of physiologists, biochemists and biologists and, possibly, have lacked an understanding of the role played by this peptide in human health and disease.

To this date, at the best of our knowledge, only one study from our group has investigated $\mathrm{T} \beta 4$ expression in the human liver in newborns and during foetal development. ${ }^{21}$ In that study, T $\beta 4$ was not detected in liver cells, in hepatocytes, in ductal cells and in oval cells of the ductal plate, whereas low levels of expression were occasionally detected in isolated cells inside the loose connective tissue of immature portal tracts. These data were in favour of a minor role of human liver in T $\beta 4$ metabolism. On the contrary, the current work evidences striking differences between the adult human liver and the newborn liver as for T $\beta 4$ immunoreactivity. The two conditions, the newborn and the adult, appear to represent the extremes of a spectrum: complete absence of the peptide in liver cells at birth, and a strong diffuse accumulation in the hepatocytes in some adults.

It is unclear why this difference in the amount of $\mathrm{T} \beta 4$ exists between adults and newborns, but our findings confirm previous reports on the ability of $\mathrm{T} \beta 4$, as well of other beta-thymosins, to change its expression during life, both quantitatively and qualitatively. In human salivary glands, we first showed a decrease in the degree of T $\beta 4$ expression from the foetus and the newborn to adults. ${ }^{23}$ Moreover, we also showed a modification of the protein expression pattern, which was granular and mainly localized inside the acinar lumen in newborns, while it appeared homogeneously diffuse to the entire cytoplasm in

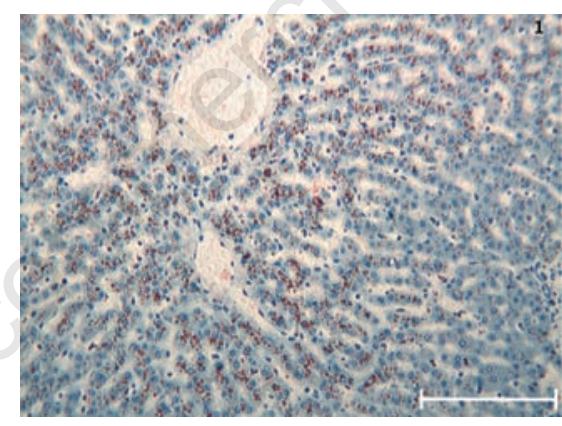

Figure 1. T $\beta 4$ immunoreactivity is localized in the periterminal hepatocytes. A minor reactivity for the peptide is detected in the periportal hepatocytes. Scale bar: $250 \mu \mathrm{m}$.

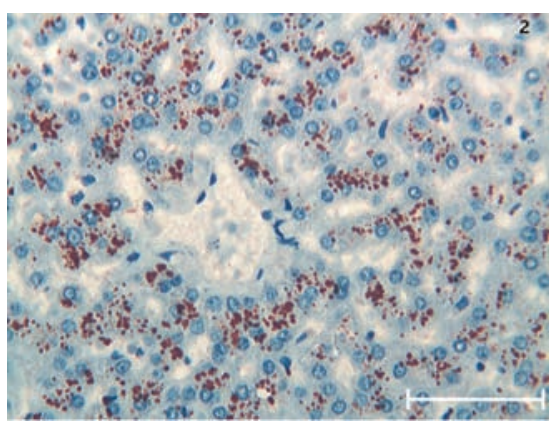

Figure 2. A strong $\mathrm{T} \beta 4$-imunoreactivity is observed in the periterminal hepatocytes. Scale bar: $400 \mu \mathrm{m}$. adults. ${ }^{23}$ The granular reactivity was interpreted as a secretory pattern, explaining the previously reported presence of large amounts of $\mathrm{T} \beta 4$ in saliva of newborns; 7 the weak homogeneous staining of the entire cytoplasm was interpreted as a structural pattern, putatively related to the G-actin binding activity of T $\beta 4$. $^{2,20}$ The present study adds strenght to a marked variability in the expression and function of T $\beta 4$ in different organs, showing a completely opposite modification in the peptide expression in the liver, characterized by the

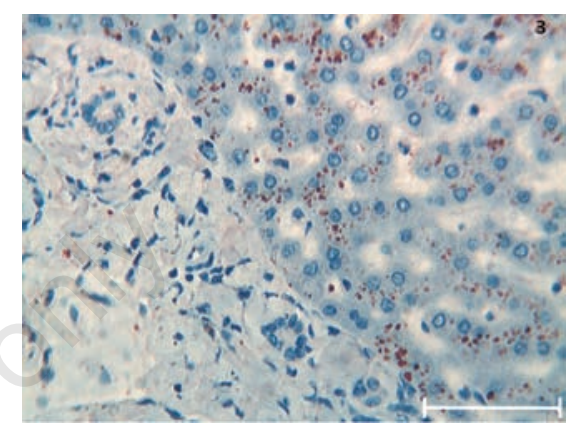

Figure 3. A lower $T \beta 4$-immunoreactivity is detected in periportal hepatocytes. Scale bar: $400 \mu \mathrm{m}$.

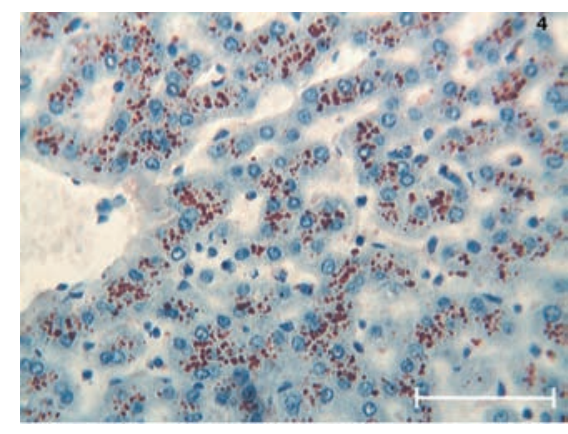

Figure 4. T $\beta 4$-reactive intracytoplasmic granules are localized at the biliary pole of hepatocytes. Scale bar: $400 \mu \mathrm{m}$.

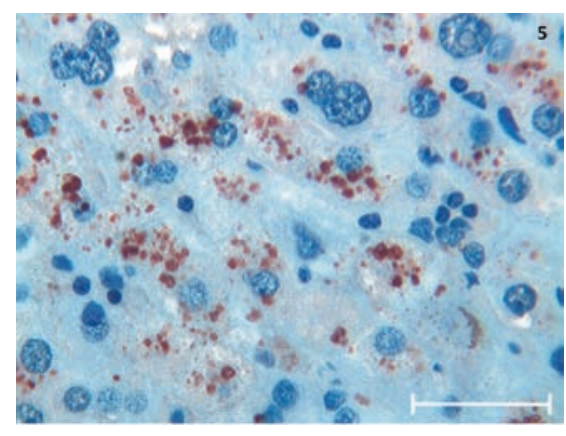

Figure 5. T $\beta 4$-reactive granules with a perinuclear distribution in the hepatocytes are detected. T $\beta 4$ immunoreactivity at the sinusoidal pole of the cytoplasm of the hepatocytes is observed. Scale bar: $400 \mu \mathrm{m}$. 
absence of T $\beta 4$ at birth and its impressive synthesis in the adult.

The high intracellular concentration of $\mathrm{T} \beta 4$ observed in normal hepatocytes deserves some consideration on the not well known activity of this versatile peptide. The main intracellular action of $\beta$-thymosins in resting cells has generally been considered their ability to sequester monomeric actin, inhibiting its ability to polymerize and therefore removing it from the cycling actin pool. ${ }^{24}$ During cell activation for cellular activities like locomotion, actin monomers are rapidly desequestrated in order to achieve the formation of actin filaments. ${ }^{2}$ As a consequence, the intracellular concentration of $\mathrm{T} \beta 4$ has been found to be particularly high in cells that rapidly respond to external signals by profound shape changes like platelets ${ }^{25,26}$ or by increased motility like polymorphonuclear cells, ${ }^{27}$ mast cells ${ }^{5}$ and macrophages. ${ }^{28,29}$ The observation in this study of large amounts of $\mathrm{T} \beta 4$ in the hepatocytes, i.e. in cells which do not rapidly change their shape or their motility, clearly supports the hypothesis that $\mathrm{T} \beta 4$ is not a simple actin monomer binding protein. ${ }^{3}$ The massive hepatic $\mathrm{T} \beta 4$ expression described in this study in some subjects, adds hepatocytes to the list of human cells able to sinthesize large amounts of the peptide in adulthood. The serum concentration of free $\mathrm{T} \beta 4$ has been estimated to range from 0.45 up to $1.1 \mu \mathrm{g} / \mathrm{L},{ }^{6}$ which is very high when compared to the concentration of insulin or glucagon, ${ }^{2}$ but comparable to the adenosin concentration. ${ }^{30}$ Such an high serum level of $\mathrm{T} \beta 4$ in the steady state can not be explained by its release by platelets during blood coagulation $^{24}$ or by leukocytes and monocytes during inflammation. ${ }^{31}$ On the contrary, the present work induces to hypothesize that the high serum content of T $\beta 4$ could, at least in part, originate by hepatocytes. Further studies correlating the hepatic T $\beta 4$ expression pattern with serum levels of the peptide will clarify the role of liver cells in plasma $\mathrm{T} \beta 4$ levels.

The preferential concentration of T $\beta 4$ in the hepatocytes of zone 3 of the liver acinus also deserves some consideration. The descending gradient from the terminal vein towards the periportal areas indicate that the peptide is mainly synthesized in zone 3 hepatocytes and, only when major quantities of $\mathrm{T} \beta 4$ are needed, even zone 2 and zone 1 hepatocytes are recruited for its additional synthesis. A similar zonation pattern, with high expression in the downstream perivenous region, has ben described for many liver enzymes, including Cytochrome P-450 $0^{32}$ and glutamine synthetase..$^{33}$ By comparison with our knowledge on the acinar gradients of liver proteins, now including $\mathrm{T} \beta 4$, much less is known about how these gradients are formed, modified and maintained. Different concentrations of oxy- gen and of humoral factors have been proposed to may create a gradient-type zonation pattern. ${ }^{32}$ In recent years, a fundamental role in mechanisms involved in patterning of liver parenchyma has been attributed to morphogens, including Wnt, $\beta$-catenin, and adenomatous polyposis coli gene. ${ }^{33}$ As for the gradient-type zonation observed in this study for $\mathrm{T} \beta 4$, our data show a marked interindividual variability, not only in the degree of expression but even in the zonation pattern. This finding suggests that the intensity of $\mathrm{T} \beta 4$ synthesis and the slope of the gradient can vary. Diurnal variations in the degree and in spatial expression have been reported for other liver enzymes, including CYP7. ${ }^{34}$ The low levels of $\mathrm{T} \beta 4$ expression in all liver biopsies from subjects positive for HBV or HCV markers (Table 1) induces to hypothesize a possible role for hepatitis-related viruses in down-regulating $\mathrm{T} \beta 4$ synthesis in infected liver cells.

In conclusion, interesting data emerge from the analysis of $\mathrm{T} \beta 4$ expression in liver cells, clearly indicating $\mathrm{T} \beta 4$ as one of the proteins synthesized by hepatocytes in normal conditions. Identifying the intimate role played by this peptide intracellularly and extracellularly, in physiology and in liver diseases, is a major challenge for future research focusing on $\mathrm{T} \beta 4$ expression in the human liver in health and disease.

\section{References}

1. Hannappel E. beta-thymosins. Ann N Y Acad Sci 2007;1112:21-37.

2. Mannherz HG, Hannappel E. The $\beta$-thymosins: intracellular and extracellular activities of a versatile actin binding protein family. Cell Motil Cytoskeleton 2009; 66:839-51.

3. Kannan L, Rath NC, Liyanage R, Lay J0 Jr. Identification and characterization of thymosin $\beta-4$ in chicken macrophages using whole cell MALDI-TOF. Ann N Y Acad Sci 2007;1112: 425-34.

4. Paulussen M, Landuyt B, Schoofs L, Luyten W, Archens L. Thymosin beta 4 mRNA and peptide expression in phagocytic cells of different mouse tissues. Peptides 2009;30: 1822-32.

5. Nemolato S, Cabras T, Fanari MU, Cau F, Fraschini M, Manconi B, et al. Thymosin beta 4 expression in normal skin, colon mucosa and in tumor infiltrating mast cells. Eur J Histochem 2010;54:e3.

6. Naylor PH, McClure JE, Spangelo BL, Low TL, Goldstein AL. Immunochemical studies on thymosins: radioimmunoassay of thymosin $\beta 4$. Immunopharmacology 1984;7:916.
7. Inzitari R, Cabras T, Pisano E, Fanali C, Manconi B, Scarano E et al. HPLC-ESI-MS analysis of oral human fluids reveals that gingival crevicular fluid is the main source of oral thymosins beta(4) and beta(10). J Sep Sci 2009;32:57-63.

8. Bodendorf S, Born G, Hannappel E. Determination of thymosin $\beta 4$ in human wound fluid after abdominal surgery. Ann N Y Acad Sci 2007;1112:418-24.

9. Badamchian M, Damavandy AA, Damavandy $\mathrm{H}$, Wadhwa S, Katz B, Goldstein AL. Identification and quantification of thymosin $\beta 4$ in human saliva and tears. Ann N Y Acad Sci 2007;1112:458-65.

10. Sanders MC, Goldstein AL, Wang YL. Thymosin beta 4 (Fx peptide) is a potent regulator of actin polymerization in living cells. Proc Natl Acad Sci USA 1992;89:467882.

11. Koutrafouri V, Leondiadis L, Avgoustakis K, Livaniou E, Czarnecki J, Ithakissios DS et al. Effect of thymosin peptides on the chick chorioallantoic membrane angiogenesis model. Biochim Biophys Acta 2001;1568:60-6.

12. Malinda KM, Sidhu GS, Mani H, Banaudha K, Maheshwari RK, Goldstein AL et al. Thymosin beta 4 accelerates wound healing. J Invest Dermatol 1999;113:364-8.

13. Badamchian M, Fagarasan M0, Danner RL, Suffredini AF, Damavandy H, Goldstein AL. Thymosin $\beta 4$ reduces lethality and downmodulates inflammatory mediators in endotoxin induced septic shock. Int. Immunopharmacol 2003; 3:1225-33.

14. Bock-Marquette I, Saxena A, White MD, DiMaio JM, Srivasta D. Thymosin beta 4 activates integrin-linked kinase and promotes cardiac cell migration, survival and cardiac repair. Nature 2004;432:466-72.

15. Shimamura R, Kudo J, Kondo H, Dohmen $\mathrm{K}$, Gondo H, Okamura S, et al. Expression of the thymosin $\beta 4$ gene during differentiation of hematopietic cells. Blood 1990;76: 977-84.

16. Chen C, Li M, Yang H, Chai H, Fisher W, Yao Q. Roles of thymosins in cancers and other organ systems. World J Surg 2005; 29:264-70.

17. Huang WQ, Wang BH, Wang QR. Thymosin $\beta 4$ and AcSDKP inhibit the proliferation of HL-60 cells and induce their differentiation and apoptosis. Cell Biol Int 2006; 30:514-20.

18. Huff T, Otto AM, Muller CS, Meier M, Hannappel E. Thymosin b4 is released from human blood platelets and attached by factor XIIIa (transglutaminase) to fibrin and collagen. FASEB J 2002;16:691-6.

19. Zuo Y, Potthoff SA, Yang HC, Ma LJ, Fogo $\mathrm{AB}$. The balance of thymosin $\beta 4$ and its metabolite Ac-SDKP modulates activity of 
profibrotic factors. Modern Pathol 2010;23 (Suppl. 1):348A.

20. Barnaeva E, Nadezhda A, Hannappel E, Sjogren MH, Rojkind M. Thymosin $\beta 4$ upregulates the expression of hepatocyte growth factor and downregulates the expression of PDGF- $\beta$ receptor in human hepatic stellate cells. Ann N Y Acad Sci 2007;1112:154-60.

21. Nemolato S, Cabras T, Cau F, Fanari MU, Fanni D, Manconi B, et al. Different thymosin Beta 4 immunoreactivity in foetal and adult gastrointestinal tract. PLoS One 2010;9:5:e9111.

22. Klein JJ, Goldstein AL, White A. Enhancement of in vivo incorporation of labeled precursors into Dann and total protein of mouse lymph nodes after administration of thymic extracts. Proc Natl Acad Sci USA 1965;53:812-7.

23. Nemolato S, Messana I, Cabras T, Manconi B, Inzitari R, Fanali C, et al. Thymosin beta(4) and beta(10) levels in pre-term newborn oral cavity and foetal salivary glands evidence a switch of secretion during foetal development. PLoS One 2009; 4:e5109.

24. Huff T, Muller CSG, Otto AM, Netzker R, Hannappel E. B-Thymosins, small acidic peptides with multiple functions. Int $\mathrm{J}$ Biochem Cell Biol 2001;33:205-20.

25. Safer D, Golla R, Nachmias VT. Isolation of a 5 -kDa actin-sequestering peptide from human blood platelets. Proc Natl Acad Sci USA 1990;87:2536-40.

26. Weber A, Nachmias VT, Pennise CR, Pring M, Safer D. Interaction of thymosin $\beta 4$ with muscle and platelet actin: implications for actin sequestration in resting platelets. Biochemistry 1992;31:6179-85.

27. Sosne G, Christopherson PL, Barrett RP, Fridman R. Thymosin b4 modulates corneal matrix metalloproteinase levels and polymorphonuclear cell infiltration after alkali injury. Invest Ophtalmol Vis Sci 2005;46:2388-95.

28. Xu GJ, Hannappel E, Morgan J, Hempstead $\mathrm{J}$, Horecker BL. Synthesis of thymosin $\beta 4$ by peritoneal macrophages and adherent spleen cells. Proc Natl Acad Sci 1982;79: 4006-9.

29. Sun H-Q, Kwiatkowska K, Yin HL. Beta- thymosins are not simple actin monomer buffering proteins. J Biol Chem 1996;271: 9223-30.

30. Cohen MV, Downey JM. Adenosine: trigger and mediator of cardioprotection. Basic Res Cardiol 2008;103:203-15.

31. Young JD, Lawrence AJ, MacLean AG, Leung BP, McInnes IB, Canas B, et al. Thymosin beta 4 sulfoxide is an antiinflammatory agent generated by monocytes in the presence of glucocorticoids. Nat Med 1999;5:1424-7.

32. Oinonen T, Lindros KO. Zonation of hepatic cytochrome P-450 expression and regulation. Biochem J 1998;329:17-35.

33. Gebhardt R, Baldysiak-Figiel A, Krugel V, Veberham E, Gaunitz F. Hepatocellular expression of glutamine synthetase: an indicator of morphogen actions as master regulators of zonation in adult liver. Prog Histochem Cytochem 2007;41:201-66.

34. Berkowitz CM, Shen CS, Bilir BM, Guibert E, Gumucio JJ. Different hepatocytes express the cholesterol 7 alphe hydroxylase gene during its circadian modulation in vivo. Hepatology 1995;21:1658-67. 